RESEARCH PAPER RP604

Part of Bureau of Standards Journal of Research, Vol. 11, October 1933

\title{
THE DEPOSITION OF CHROMIUM FROM SOLUTIONS OF CHROMIC AND CHROMOUS SALTS
}

\author{
By Charles Kasper
}

\section{ABSTRACT}

The confusing and apparently contradictory literature on the electrodeposition of chromium from trivalent and bivalent salts was critically examined and pertinent experiments were performed.

The main obstacle to obtaining bright deposits at high efficiency is not, as formerly supposed, in keeping the solutions of trivalent chromium violet; that is, preventing the formation of green undissociated molecular ions; but in maintaining a low concentration of hydrogen ions and a high concentration of chromium ions in the cathode film. The use of chromous salts or of chromic complexes does not circumvent this difficulty. The chromic acid bath is inherently superior to those containing chromium in the lower valence states.

\section{CONTENTS}

I. Introduction

II. Historical review

III. Baths containing simple trivalent salts

1. Theory

2. Experimental work

IV. Baths containing chromous salts

V. Baths containing complex chromium compounds . .

VI. Comparison of results with chromic acid bath

VII. Conclusions

VIII. Acknowledgments .

IX. Bibliography

\section{INTRODUCTION}

All commercial chromium plating is conducted in chromic acid baths, in which the chromium is sexivalent and is deposited with a low cathode efficiency. Bright deposits are obtained only over a limited range of current density and the throwing power is poor. It has been believed that this relatively poor performance is associated with the fact that the deposition occurs from the higher state of oxidation, and that better results would be obtained with lower states of oxidation. A bath of the latter type would more closely approximate the usual plating bath, whose performance leaves little to be desired in the case of nickel, zinc, and iron. A large number of investigations have been made on the deposition of chromium from the lower states of oxidation, but no such baths are at present in commercial use.

The purpose of this investigation was to consider critically the contradictory literature on this subject and to make further experiments that appeared to have promise. To warrant adoption, any 
new type of chromium bath should be at least equal, or preferably superior, to the chromic acid bath in the following respects: (1) It should produce deposits that are bright, or which can readily be buffed bright; (2) it should produce such deposits over a fairly wide range of temperature and current density, and preferably at room temperature and at a relatively low current density; (3) the cathode efficiency should be at least equal to 15 percent as calculated for sexivalent chromium (which is equivalent to only 7.5 percent for trivalent or 5 percent for bivalent chromium); (4) the baths should be inexpensive, simple, stable, and easily controlled.

Failure to describe accurately the deposits obtained probably accounts for some of the contradictions in the literature, and especially some of the very high cathode efficiencies that have been reported for good plate. Dark, spongy, or impure deposits are practically useless for electroplating. Although the above requirements are very moderate, especially in view of the limitations of the present chromic acid baths, the net result of this survey and research is the conclusion that they are not met by any bath thus far developed, and there is little reason to believe that they can be met.

\section{HISTORICAL REVIEW}

Chromium was first deposited from the trivalent state by Junot (1). ${ }^{1}$ Bunsen (2) worked with a chromous-chromic bath in a porous pot and obtained a bright deposit at an elevated temperature and a high current density. He emphasized the importance of the chromous ion. Placet and Bonnet (5) patented the use of trivalent chromium baths with lead anodes. In some of their patents the addition of alkali or alkaline earth chlorides was specified. Moeller and Street (3) worked at elevated temperatures with a concentrated solution of chrome alum to which a large amount of sodium sulphate was added. A diaphragm was employed and efficiencies of about 40 percent were obtained. Cowper-Coles (4) used a similar system in which the bath consisted of an acidified chromic chloride solution. Fereé (6) also used a highly acidified chromic chloride solution and obtained very pure metal. From concentrated solutions of chromic chloride and potassium chloride, he obtained good deposits on platinum with 45 percent efficiency. Neumann and Glaser (7) obtained steel-gray metal from solutions of the sulphate and chloride in a porous pot with efficiencies of about 50 percent. They found that elevated temperatures were detrimental to the character of the deposits. On carbon cathodes they obtained an efficiency of 85 percent. Chromic acetate was found to yield poor results. LeBlanc $(\delta)$ was unable to prepare chromium by the methods of Placet and Bonnet, but with porous pots he obtained traces of metal. The baths that he found satisfactory can be regarded as acioified chrome alum solutions. Carveth and Mott (9) made a rather extensive research on deposition from solutions of chromic chloride and chromic sulphate in porous pots. They proved the importance of chromous ions in their baths. They found that high temperatures were detrimental to the character of the deposit and to the efficiency of deposition. They reported efficiencies varying from 10 to 50 percent, with good deposits at efficiencies around 30 percent. Dony-Henault (10) analyzed the

\footnotetext{
1 The numbers in parentheses here and throughout the text refer to the bibliography at the end of the paper.
} 
data of Carveth and Mott and concluded that the detrimental temperature effect reported was due to the formation of the green form ${ }^{2}$ of chromic salts at elevated temperatures. He therefore predicted that successful deposits would depend on the chromic ion being in the violet form. This idea seems to have captured the imagination of electrochemists and has often been employed by them as a requisite of the desired solution. Voisin (13) was unsuccessful in repeating the work of Placet and Bonnet, but succeeded in duplicating Fereé's results. Sigrist, Winkler, and Wantz (17) stressed the importance of a diaphragm for the best results. From a chemical analysis of the deposits they concluded that the chromic acid bath is superior to baths of trivalent chromium.

Traube, Burmeister, and Stahn (18) worked with chromous solutions and obtained very impure dark deposits, but with bigh efficiencies. Pamfilov and Fillippuichev (24) used basic chromic sulphate solutions at room temperature and obtained fair results; the maximum efficiency found was 25 percent. Britton and Westcott (28) investigated sulphate and chloride solutions, both with and without diaphragms. They confirmed many of Carveth and Mott's results but failed to obtain their high efficiencies. An approximate analysis of the deposits showed them to be very impure. They recommended the use of a diaphragm and the addition of alkali salts, and emphasized the importance of the control of the hydrogen ion concentration. Fuseya and Sasaki (26) worked with trivalent chromium baths and reached the conclusion that for successful deposition the green form of the saits must be used and that the acidity must be regulated. It is noteworthy that they recommend the use of green rather than violet salts. Pamfilov and Federov (31) carried out experiments similar to those of Pamfilov and Fillippuichev but with plates instead of wires as cathodes, and obtained poor deposits and very low efficiencies. Britton and Westcott (32) followed up the ideas developed in their first research and investigated chromic acetate and complex tartrates and oxalates. The results were very unsatisfactory except with ammonium chromi-oxalate, which had been previously shown by Mazzuchelli (25) to give good deposits but with very low efficiencies. With complex citrate baths Yntema (33) obtained very good deposits. Liebreich (16) recommended the use of alkaline chromites.

As it is not certain that the investigators who got good plate really obtained deposits that were of commercial quality, it was considered advisable to investigate the problem from this point of view. Attention was therefore focused on the cathode processes, and in particular on the conditions for the best deposits. The above-cited literature indicates that both violet and green forms of chromic salts may be used, and that the chromous state is important. The solutions must be slightly acid and should preferably contain a large amount of alkali salt. For best results a diaphragm must be employed.

${ }^{2}$ For example, the violet chloride $\left[\mathrm{Cr}\left(\mathrm{H}_{2} \mathrm{O}\right)_{6}\right] \mathrm{Cl}_{3}$, is transformed by heating into the green compounds $\left[\mathrm{Cr}\left(\mathrm{H}_{2} \mathrm{O}\right)_{5} \mathrm{Cl}\right] \mathrm{Cl}_{2}$ and $\left[\mathrm{Cr}\left(\mathrm{H}_{2} \mathrm{O}\right)_{4} \mathrm{Cl}_{2}\right] \mathrm{Cl}$. 


\section{BATHS CONTAINING SIMPLE TRIVALENT SALTS}

\section{THEORY}

The chemistry of trivalent chromium is complex and no one theory will explain the electrodeposition from all the possible compounds. The principal compounds existing in neutral and moderately acid aqueous solutions may be considered to fall into four classes.

Class I. The trivalent chromium exists as the violet hexa-aquo ion, $\left[\mathrm{Cr}\left(\mathrm{H}_{2} \mathrm{O}\right)_{6}\right]^{+++}$, in conjunction with anions that do not exhibit a marked tendency to form molecules or molecular ions at room temperature. When the temperature is raised, an irreversible transformation occurs, which may be partial or complete. The resulting form may be a complex electrolyte (a positive molecular ion), an undissociated molecule, or a colloid. This behavior is known to occur with the chloride, bromide, and sulphate. The fluoride can be made to undergo the transformation but not by merely heating.

Class II. The violet hexa-aquo ion exists in conjunction with anions that do not exhibit any marked tendency for the formation of the green form even when the solution is heated. This class is exemplified by the nitrate, ${ }^{3}$ perchlorate, fluosilicate,${ }^{4}$ and fluoborate. ${ }^{5}$ Molecules and molecular ions containing the chromic ion and the negative radicles are absent.

Class III. The hexa-aquo ion is in equilibrium with a highly dissociated molecular ion. The only known member of this class is chromium dichromate.

Class IV. The trivalent chromium is bound strongly with the negative radicle to form undissociated molecules or negative molecular ions. The fluoride and sulphate give rise to this condition in special instances, but it is more frequently encountered with the organic anions such as acetate, oxalate, tartrate, and citrate.

The simple trivalent chromium salts are members of classes I and II. There has been a difference of opinion whether the violet or the green salt is preferable for electrodeposition from trivalent baths; both sides have brought forth apparently incontrovertible evidence. The majority of electrochemists assume that the violet form is necessary and that the difficulty of chromium plating is in keeping the salt violet. This idea owes its origin to Dony-Henault, whose original statement was, however, based upon false premises. $\mathrm{He}$ made this assumption to account for the fact that Carveth and Mott found that the baths operated at temperatures above $50^{\circ} \mathrm{C}$. were inferior to those operated at lower temperatures. Dony-Henault pointed out that this is consistent with the fact that the green form is favored at high temperatures and the violet at low. It so happens that the puce ${ }^{6}$ form of chromic chloride employed by Carveth and

\footnotetext{
3 Strictly the nitrate is intermediate between classes I and II.

4According to the author's theory (34) of chromium deposition from the chromic acid bath, any anion of this second class is ineffective as an addition agent (as a substitute for sulphate). It would appear, therefore, that the proposed use (29), (30), of the fluosilicate in such a capacity is contrary to the theory. As emphasized in one of the patents (29) the fluosilicate merely acts as a source of fluoride, which latter is an effective addition agent. The instability of chromium:fluosilicate was first established by Recoura (14). The apparent effectiveness of the fluosilicate ion as an addition agent to the chromic acid bath was first reported by Müller (20).

5 That this ion should exhibit this characteristic is in accordance with the isomorphism of the perchlorate and fluoborate, as brought forth by Wilke-Dorfurt (19). It is interesting to note that the stable anions in this class are the ones that give the most satisfactory lead deposits, perhaps because they do not form molecules or molecular ions that include lead. This shows that complex ions are always not necessary for good deposits, though they are used in many plating baths for getting the best deposits.

The lavender anhydrous chromic chloride whose solution can be effected only by employing chromous salts as catalysts.
} 
Mott is known to give $\left[\mathrm{CrCl}_{2}\left(\mathrm{H}_{2} \mathrm{O}\right)_{4}\right] \mathrm{Cl}$ when dissolved. The sulphate which they employed was green. Most of the work has been done with the green salts, as they are the most common.

If the development of the proper bath (as has been suggested) merely depends on finding a salt that always remains violet, the solution of the problem would consist in selecting the most practical salt of class II. The electrochemically unstable nitrate and perchlorate ${ }^{7}$ are ruled out. The fluosilicate is likewise eliminated for reasons previously mentioned. Accordingly, then, the logical salt to use would be the fluoborate.

In considering the principles of deposition from trivalent baths we shall assume a system in which only the simple, violet hexa-aquo chromic ion is present; the green form and the chromous ion are absent. The process of electrodeposition from such a system consists in effecting a reaction with a positive free energy change, the minimum value of which is given by the standard free-energy change. In actual electrolysis, the true value will be markedly different owing to polarization, but the relation of the free energy to that of another similar reaction of a different metal will not change appreciably. This amounts to saying that that portion of the polarization which is not dependent on the hydrogen overvoltage will be approximately the same for all systems considered. If this may be considered a close approximation in this case, it gives an illuminating picture of the results to be expected and which are actually found. Hence, if we compare the zinc and nickel baths with the case in hand, we should be able to show whether plating at high efficiencies is at all possible.

The energy of deposition of zinc is considerably higher than that of nickel. However, zinc possesses a high hydrogen overvoltage compared to that of nickel. Therefore, although zinc may not flash as well as nickel, once the cathode is covered with zinc the latter can be deposited with as high an efficiency as nickel. The situation with trivalent chromium is somewhat different. Its free energy of deposition is intermediate between that of nickel and zinc. Its hydrogen overvoltage ${ }^{8}$ is even lower than that of nickel, hence, unlike zinc, it cannot be deposited with as high an efficiency as nickel with the same $\mathrm{pH}$ prevailing in the bulk of the solution. It is not possible to calculate the hydrogen-ion concentration of the cathode film from overvoltage data or from $\mathrm{pH}$ determinations in the bulk of the solution. There is little doubt, however, that in zinc and nickel deposition a hydrogen-ion concentration as low as $10^{-6}$ prevails. We shall assume conservatively that it is a $10^{-5}$. It is then possible to show from the standard electrode potentials of chromium $(-0.5 \mathrm{v})$ and of nickel $(-0.23 \mathrm{v})$ that a hydrogen-ion concentration of not greater than $10^{-8}$ must exist in the cathode film before chromium can be deposited efficiently. This condition is impossible with an easily hydrolyzed ion like the violet chromic ion, which is completely precipitated at a hydrogen-ion concentration of about $10^{-5}$.

The question arises as to just what differences are to be expected between the violet and green forms of class I, and as to whether the green compounds present a means of circumventing the difficulty.

7 At the high current densities that must be employed in chromium deposition.

8 No reliable values of the overvoltage on chromium have been reported, but experience in chromium plating indicates that it is considerably below nickel. 
The usual $\mathrm{pH}$ determinations indicate (erroneously) that the green form is more readily hydrolyzed than the violet. Actually, however, the violet salts are more highly hydrolyzed than the green, which is demanded theoretically by the fact that the violet ion is more highly charged and has a smaller radius. The erroneous result is due to the formation of extraneous basic salts. If, as Bjerrum (11) has done, steps are taken to eliminate them or to use data that do not involve them, the hydrolysis constants fall in the expected order. The differences in free energy between the violet and the green forms have never been extensively measured, but the differences in heat content have been. Unfortunately this is a type of reaction in-which Thomson's rule cannot be used to estimate the free energy change from the heat content change. However, as the two forms are coexistent and as equilibrium can be established between them, it follows that the free energy difference is small and of such a sign that the green form is favored at temperatures of $50^{\circ} \mathrm{C}$ and above; the violet is preferred at lower temperatures. This is in accordance with the few measurements of Demassieux and Heyrovsky (23). From a consideration of the hydrolysis constants, it might be concluded that with green solutions it should be possible to operate with a lower hydrogen-ion concentration than with the violet. However, it is an experimental fact that the point of precipitation of the hydroxide is roughly independent of whether the violet or green salts are used. This is caused by the fact (shown by Bjerrum) that the transition from the green to the violet form involves a basic salt as an intermediate step.

It follows from this analysis that no material advantage can be gained by working with the green salts. If, as will be shown later, the performance of the bath is largely dependent on the accumulation of chromous ions, the violet form should give better results than the green because, as Traube and Goodson (15) have shown, the efficiency of reducing trivalent chromium to the chromous state is much higher for the violet than for the green form. At room temperature the green form is more difficult to reduce than the violet form, even though it represents a higher (presumably more active) energy state. The explanation of this behavior lies in the modern interpretation of the process of electrolytic reduction (27). If we have two systems representing equal energy states, the reduction of the form that approaches the closer to the cathode occurs the more readily. At all events, there is no indication that baths having high efficiency are realizable with any members of class I or class II.

\section{(2.) EXPERIMENTAL WORK}

As stated, the primary aim was to see whether a trivalent bath could be developed which is comparable to the chromic-acid bath. The definition of the proper conditions for obtaining a bright deposit was largely empirical. Having once located the range of conditions of best deposits for a particular solution, the temperature, concentration, current density, and acidity were altered, in order to find the optinum conditions for obtaining a satisfactory deposit.

In order to test the common assumption that a permanently violet bath should give good deposits, a solution of chromic fluoborate, which had been predicted and shown to be a member of class II, was studied. Unlike most violet salts, the fluoborate, as expected from its 
similarity to the perchlorate, is extremely soluble and there is little doubt that it is a strong electrolyte. The useful life of this bath (and of any trivalent chromium bath) was extremely short, because by its hypersensitivity to traces of heavy metals like copper. ${ }^{9}$ Copper cathodes were generally used. The bath was about $1.8 \mathrm{M}$ in trivalent chromium and contained free fluoboric acid, the concentration of which was varied to produce pH values from 1 to 3 . No sulphate was present. It was established that bright chromium could be deposited with free acid, corresponding to a $\mathrm{pH}$ of 1.3 at $40^{\circ} \mathrm{C}$. and $20 \mathrm{amp} / \mathrm{dm}^{2}$. These deposits were "white", in comparison with the blue chromium obtained from the chromic-acid bath. The cathode efficiency of the best deposits was about 3 percent. There is little doubt that these conditions represent roughly the best performance of this bath. It is to be noted that the best deposits were obtained at rather high current densities. It was found that the plating range was exceedingly narrow, and that uniformly bright deposits could be obtained only when extreme precautions were taken to insure an even current distribution over the entire plate, which was done by shielding the edges. The oxidation of trivalent chromium was high at the magnetite anode, much higher than that found with the chromealum solution. There was nothing in the large number of experiments performed to indicate that the chromic fluoborate was markedly superior to other chromic salts such as potassium chromic sulphate.

More extensive experiments were made with potassium chromic sulphate solutions. Preliminary experiments showed that it was difficult to obtain good deposits from solutions of this salt alone. It was necessary to add an alkali salt (sodium sulphate), and free acid, which required the use of high current densities. As indicated in the introduction, operation at a low current density would be particularly desirable. For this reason, a rather extensive study was made of baths with a low acid content, but the quality of the deposit deteriorated as the acidity was reduced. Hence the operation of a trivalent chromium bath at low current density does not seem feasible. A Haring cell (21) was employed on these experiments to get uniform current distribution. The most satisfactory solution found contained $100 \mathrm{~g} / \mathrm{l}$ of $\mathrm{KCr}\left(\mathrm{SO}_{4}\right)_{2} .12 \mathrm{H}_{2} \mathrm{O}, 300 \mathrm{~g} / \mathrm{l}$ of $\mathrm{Na}_{2} \mathrm{SO}_{4}$, and $12 \mathrm{~g} / \mathrm{l}$ of $\mathrm{H}_{2} \mathrm{SO}_{4}$. Bright deposits with a cathode efficiency of 6 percent were obtained at $30^{\circ} \mathrm{C}$ and at about $9 \mathrm{amp} / \mathrm{dm}^{2}$. These deposits were almost of commercial quality, ${ }^{10}$ but they were somewhat pitted and a perfect plate was never obtained. Even this result was difficult to obtain on account of the extremely narrow plating range. Variations of 5 percent from the optimum current density gave a completely dull deposit. The dull deposits were, however, fairly uniform in texture. The usual deposits obtained under the optimum conditions had a blotched appearance with dull and bright areas on various sections of the plate. A few uniformly bright deposits were obtained, but the unusually narrow plating range could not be widened by any variations.

As the development of a high-efficiency bath from simple trivalent salts is fundamentally unsound, further work in that direction was

\footnotetext{
9 This fact would limit the commercial application to steel and nickel-plated cbjects. No other investigator seems to have called attention to this fact. It is possible to ruin the best bath by merely letting the copper cathode stand in the solution for a short time.

10 Those deposited on a copper base left a dark residue on solution in acid, while those on nickel did not.

This dark material is undoubtedly caused by the copper and not by any inherent p roperty of the bath.
} 
abandoned. The narrowness of the plating range can be readily explained if we assume that two processes are effective. It is only under extremely restricted conditions that two such widely divergent systems as chromic and chromous salts can be expected to yield a bright deposit. A variation of efficiency with time of operation of the bath was observed by Carveth and Mott and by Britton and Westcott (28). This effect was undoubtedly caused by the accumulation of chromous salts on continued electrolysis. It was not observed in the experiments reported here, in which no diaphragm was used; obviously such an effect will be small in the absence of a diaphragm, because the accumulation of a strong reducing agent like chromous ion would be impossible with an insoluble anode in the solution. If the presence of the chromous ion increases the efficiency, it might be desirable to use an entirely chromous solution.

\section{BATHS CONTAINING CHROMOUS SALTS}

Chromous salts might be advantageous for two reasons, first, the energy required for deposition is lower, and second, the cathode film can reach a lower hydrogen ion concentration without precipitation of the hydroxide. Although no data exist on the hydrolysis of the chromous ion, it is likely that, as a bivalent ion, it hydrolyzes considerably less than a trivalent ion like the chromic. These two factors would assist in the attainment of a higher efficiency. However, it can be shown by reasoning similar to that already employed that there is no promise of an efficiency approaching that of nickel deposition.

Bunsen (2) obtained bright deposits from a chromous solution. Traube, Burmeister, and Stahn (18) got poor deposits from pure chromous solutions, but with very high efficiencies. Carveth and Mott (9) obtained high efficiencies, and stated that good deposits could be obtained with an efficiency of 30 percent. However, Britton and Westcott (28) failed to find such high efficiencies. The discrepancy can be readily explained by differences in technique. Carveth and Mott employed parchment separators whereas Britton and Westcott used ordinary clay ones. It is known that silica surfaces catalyze the oxidation of chromous ions by hydrogen ions. Further, Britton and Westcott stirred their solution, which is certainly not conducive to the accumulation of a large concentration of chromous ion. The use of concentric electrodes, which give good current distribution, leads to better results, as Pamfilov and Federov (31) have shown.

The first experiments were done with green chromic sulphate ${ }^{11}$ in the cathode chamber, and with an auxiliary cathode of carbon. ${ }^{12}$ An alundum porous pot was used, and the anode compartment contained either sodium sulphate or sulphuric acid or both. The entire apparatus was placed in a closed container through which carbon dioxide was passed continuously. The oxygen evolved at the anode was allowed to escape directly. The volume of liquid in the cathode compartment was three liters and that of the anode, $300 \mathrm{ml}$. With this relatively large apparatus, the conditions of plating were fairly constant. The initial concentration of chromic sulphate was three molar. Although no analysis was made to determine the degree of

11 Chromic chloride could not be used (in the apparatus employed) on account of the free chlorine which forms at the anode and diffuses to the cathode where it prevents the accumulation of chromous ions.

12 The usual lead cathode cannot be used on account of the poisoning action of the lead on the deposit. 
reduction, this was certainly much higher than could be obtained with open vessels. The best results were obtained with neutral chromic sulphate in the cathode and sodium sulphate in the anode compartment. Even the best bright deposits had a dark sheen on them. The most striking feature was that the plating range was still extremely narrow. Bright deposits were obtained at $10 \mathrm{amp} / \mathrm{dm}^{2}$ at $30^{\circ} \mathrm{C}$. and the efficiency was 3 percent on the basis of bivalent chromium.

Solutions of pure chromous sulphate were prepared by dissolving electrolytic chromium in sulphuric acid in a closed apparatus with the air displaced by carbon dioxide. The first solution was $1.5 \mathrm{M}$ in chromous sulphate and $0.05 \mathrm{~N}$ in free acid. A saturated solution of sodinm sulphate was used in the anode compartment. Again the bright plating range was found to be very narrow, in fact no entirely bright plate was produced. At $30^{\circ} \mathrm{C}$., the best deposit was obtained at 30 $\mathrm{amp} / \mathrm{dm}^{2}$. The efficiency for a dull plate at a current density just above that for the bright plate was 12 percent for trivalent, or 8 percent for bivalent chromium; for the bright plate it must have been lower.

A more nearly neutral solution was obtained by adding insufficient acid to dissolve all the chromium. The salt concentration was approximately the same as in the previous case. From this solution no metal was deposited but merely brown chromous oxide.

Experiments under widely different conditions failed to reveal any wide plating range for chromous solutions, although high efficiencies were readily obtained for dull, impure deposits. It is at least probable that the reported high efficiencies for chromous or partially chromous solutions were obtained under conditions that gave commercially unsatisfactory deposits.

The surprising similarity in behavior between the chromous and chromic baths may be readily explained if the possible processes are considered. When conditions at the cathode permit the deposition of metallic chromium, the chromous ion is in a state where it can readily undergo exchanges of energy with the cathode; that is, it can be reduced by electrons from an external source. These same conditions permit the chromous ion to undergo any other chemical reaction that may be hindered in solution, but which may occur on the surface of the cathode. There are two such reactions, $(a)$ the autooxidation and reduction of chromous ion $\left(3 \mathrm{Cr}^{++} \rightarrow \mathrm{Cr}+2 \mathrm{Cr}^{+++}\right)$, and (b) the reaction between chromous ion and hydrogen ion $\left(\mathrm{Cr}^{++}+\mathrm{H}^{+} \rightarrow\right.$ $\left.\mathrm{Cr}^{+++}+1 / 2 \mathrm{H}_{2}\right)$. Thermodynamic evidence shows that the first reaction is insignificant, but that the second is not, as it has a standard free energy change of $-9 \mathrm{~kg}$ calories. It is known that the oxidation of the chromous ion by the hydrogen ion can be influenced by surface catalysts, particularly metals of a low hydrogen overvoltage. It has been shown (12) that the rate-determining step is the rate of diffusion of the solution to the metal. Since the cathode accelerates the frequency and ease of contact by virtue of its negative charge, and for the same reason work is put into the system, the reaction will occur very much more readily at a cathode than on an uncharged metal. It is hence impossible to obtain chromous ions on the surface of any metal, such as chromium, which possesses a low hydrogen overvoltage, without the production of a relatively large amount of chromic ions. Therefore the performance of the chromous bath will be similar to that of the chromic. The only essential difference is 
that the chromous bath can be operated at higher current densities without the production of green oxide. This condition does not make an acid chromous bath promising. There are three ways for possible improvement: $(a)$ to employ a base metal of a high hydrogen overvoltage, $(b)$ to use very high current densities, and $(c)$ to operate at a high $\mathrm{pH}$. The first is automatically excluded by the properties of chromium, the second is undesirable, and the third is, as has been shown, impracticable.

\section{BATHS CONTAINING COMPLEX CHROMIUM COMPOUNDS}

Various possible methods of circumventing the difficulty that makes the operation of the simple trivalent chromium bath unfavorable as compared with the chromic acid bath have been discussed. Britton and Westcott (32) were quite aware of this difficulty, so they proposed to employ complex salts (members of class IV) of trivalent chromium which can exist in alkaline solutions without precipitating the hydroxide. This idea presents, according to Britton and Westcott, a valid means of circumventing the difficulty. However, the low metal ion concentration that makes the precipitation of the hydroxide difficult also makes the reduction of the trivalent chromium more difficult. This is an inescapable thermodynamic fact. Although no material improvement in efficiency can be expected, it may be that wider plating ranges can be obtained.

Britton and Westcott worked with chromium acetate, tartrate and oxalate. With ammonium chromi-oxalate they could obtain good deposits over a rather wide range but at very low efficiencies (less than 1 percent). The other solutions were worse than the simple salts. Mazzuchelli (25) has shown that such a bath would work, but at exceedingly low efficiency. There is a recent patent (22) which purports to describe a successful chromium chloride bath. This bath was apparently designed following the axiom of Dony-Henault. To obtain violet solutions the inventors added nitrate (which is likely to be reduced to ammonia) and oxalic acid. Ammonium salts were also added. Apparently the color of the chromi-oxalate was confused with that of the violet hexa-aquo ion. There is little doubt that the resulting bath reached a state in which it was principally the ammonium chromi-oxalate. The character of the deposit and the exceedingly low efficiency obtained in experiments on their baths confirm this conclusion.

Yntema (33) recommended the use of citrates. This work was repeated. The best deposits were lustrous, but dark, and the efficiencies were less than 1 percent.

\section{COMPARISON OF RESULTS WITH THE CHROMIC ACID BATH}

A comparison of the trivalent chromium bath with the chromic acid bath will make clear why it seems improbable that a trivalent or bivalent bath can be designed which will be superior to the sexivalent bath. In a previous paper on the theory of chromium deposition (34), it was pointed out that the reduction of chromic acid to metal is an even more probable process thermodynamically than the liberation of hydrogen. That is, if it were possible to construct a reversible cell 
which would be capable of yielding all possible degrees of reduction of chromic acid in their proper thermodynamic order, we would find chromium metal coming out before the liberation of hydrogen. With the trivalent state, the situation is the reverse, hydrogen would be liberated before the deposition of chromium. This argument is based on the plausible theory that in the chromic acid bath reduction occurs directly from the sexivalent state. A research is now in progress to confirm this hypothesis.

Further, it was proved that the deposition actually occurred with the cathode film quite acid ( $\mathrm{pH}$ approximately 3 ). Thus we see that the deposition of chromium from a strong oxidizing agent presents a means of circumventing the difficulty that renders the trivalent bath impracticable. There is no doubt that trivalent chromium, under the conditions of acidity that obtain in chromium deposition from the chromic acid bath, would yield a current efficiency which would be considerably lower. That is only possible with a strong oxidizing agent. The difference between the chromic acid bath and the trivalent bath is exceedingly large when looked at from this point of view, and we do not see how any manipulation of the controllable factors can overcome this enormous difference.

If a superior chromium bath is to be made it will not lie in the direction of lower states of oxidation.

\section{CONCLUSIONS}

(a) Simple trivalent chromium baths yield poor deposits at low efficiencies. The bright plating range is exceedingly narrow; $(b)$ Chromous baths give results which are similar to those of the trivalent baths; (c) The use of complexes in order to solve the difficulties inherent in the trivalent bath is unsound; $(d)$ The chromic acid bath is inherently superior to solutions containing lower valence compounds.

\section{ACKNOWLEDGMENTS}

The author is indebted to William Blum for suggestions and advice and to M. R. Thompson for measurements of $\mathrm{pH}$.

\section{BIBLIOGRAPHY}

(1) C. J. E. Junot, Brit. Pat. 1,183, 1853.

(2) R. Bunsen, Pogg. Ann., vol. 91, p. 119, 1854.

(3) J. F. L. Moeller and E. A. G. Street, Brit. Pat. 18,743, 1899.

(4) S. O. Cowper-Coles, Chem. News, vol. 81, p. 16, 1900.

(5) E. Placet and J. Bonnet, Bull. Soc. Chim., vol. 3, 25, p. 620, 1901.

(6) J. Fereé, ibid., vol. 3, 25, p. 617, 1901.

(7) B. Neumann and G. Glaser, Z. Elektrochem., vol. 7, p. 656, 1901.

(8) M. LeBlanc, Darstellung des Chroms, 1904.

(9) H. R. Carveth and W. R. Mott, J. Phys. Chem., vol. 9, p. 231, 1905.

(10) O. Dony-Henault, Z. Elektrochem., vol. 12, p. 329, 1906.

(11) N. Bjerrum, Z. physik. Chem., vol. 59, p. 596, 1907.

(12) K. Jablczynski, Z. physik. Chem., vol. 64, p. 748, 1908.

(13) J. Voisin, Revue Métallurgie, vol. 7, p. 1137, 1910.

(14) A. Recoura, Compt. rend., vol. 157, p. 1525, 1913.

(15) W. Traube and A. Goodson, Ber., vol. 49, p. 1619, 1916.

(16) E. Liebreich, Brit. Pat. 164,731, 1921.

(17) J. Sigrist, P. Winkler, and M. Wantz, Helv. Chim. Acta, vol. 7, p. 968, 1924.

(18) IV. Traube, E. Burmeister, and R. Stahn, Z. anorg. Chem., vol. 147, p. 50,1925 . 
(19) E. Wilke-Dorfurt and G. Balz, Z. anorg. Chem., vol. 159, p. 197, 1926.

(20) E. Müller, Z. Elektrochem., vol. 32, p. 399, 1926.

(21) H. E. Haring, Trans. Am. Electrochem. Soc., vol. 49, p. 417, 1926.

(22) J. F. K. McCullough and B. W. Gilchrist, Brit. Pat. 292,094, 1927.

(23) N. Demassieux and J. Heyrovsky, J. chim. phys., vol. 26, p. 219, 1929.

(24) A. V. Pamfilov and G. F. Filippuichev, J. Russ. phys. Chem., vol. 61, p. $2221,1929$.

'25) A. Mazzuchelli, Atti Accad. Lincei, vol. 12, p. 587, 1930.

26) G. Fuseya and K. Sasaki, Trans. Electrochem. Soc., vol. 59, p. 445, 1931.

(27) R. W. Gurney, Proc. Roy. Soc., vol. 134A, p. 137, 1931.

(28) H. T. Britton and O. B. Westcott, Trans. Faraday Soc., vol. 27, p. 809, 1931.

(29) C. G. Fink and H. D. McLeese, U.S. Pat. 1,844,751, 1932.

(30) D. T. Ewing, U.S. Pat., 1,864,014, 1932.

(31) A. V. Pamfilov and O. S. Federov, J. Gen. Chem. (U.S.S.R.), vol. 2, No. 2, p. 208, 1932.

(32) H. T. S. Britton and O. B. Westcott, Trans. Faraday Soc., vol. 28, p. 627, 1932.

(33) L. F. Yntema, J. Am. Chem. Soc., vol. 54, p. 3775, 1932.

(34) C. Kasper, B.S. Jour. Research, vol. 9, p. 353, 1932.

Washington, July 29, 1933. 